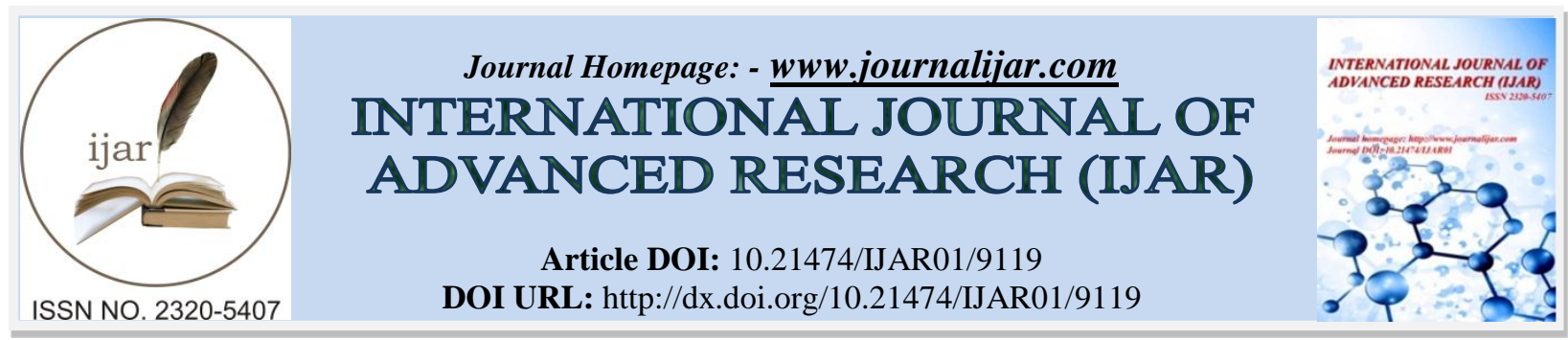

RESEARCH ARTICLE

\title{
DEVELOPMENT AND VALIDATION OF UV- VISIBLE SPECTROPHOTOMETER METHOD FOR ESTIMATION OF RIVASTIGMINE IN HUMAN PLASMA.
}

\author{
Dr. K. Bhavyasri*1, M.Sreshta ${ }^{1}$ and Dr. D. Rambabu ${ }^{2}$.
}

1. Department of Pharmaceutical Analysis, RBVRR Women's College of pharmacy, Barkatpura, Hyderabad, Telangana, India.

2. Gland Pharma Pvt Ltd, Gandimaisamma, Hyderabad,Telangana,India.

\section{Manuscript Info}

Manuscript History

Received: 22 March 2019

Final Accepted: 24 April 2019

Published: May 2019

\begin{abstract}
The main purpose of this study was to develop a simple precise, rapid and accurate uv-visible spectrophotometric method for determination of rivastigmine in spiked human plasma by extracting the Rivastimine from spiked human plasma using methanol after extraction it was scanned between $200-400 \mathrm{~nm}$ by using uv detector and its absorbance maxima was found to be $270 \mathrm{~nm}$.the calibration curve was linear in the range of $6-15 \mathrm{ppm}$.the recovery and assay studies of rivastigmine were within 99 to $102 \%$ indicating that the proposed method can be quality control analysis of rivastigmine.
\end{abstract}

Copy Right, IJAR, 2019,. All rights reserved.

\section{Introduction:-}

Rivastigmine is chemically 3-[(1S)-1- (dimethyl amino) ethyl] phenyl N-ethyl-N-methylcarbamate. Rivastigmine (sold under the trade name Exelon among others) is a acetylcholinesterase inhibitor used for the treatment of mild to moderate Alzheimer's disease and Parkinson's. It is a carbamate derivative that is structurally related to physostigmine, but not to donepezil and tacrine. The precise mechanism of rivastigmine has not been fully determined, but it is suggested that rivastigmine binds reversibly and inactivates cholinesterase (e.g. acetylcholinesterase, butyryl cholinesterase), preventing the hydrolysis of acetylcholine, and thus leading to an increased concentration of acetylcholine at cholinergic synapses.

The anticholinesterase activity of rivastigmine is relatively specific for brain acetylcholinesterase and butyryl cholinesterase compared with those in peripheral tissues. It belongs to the pregnancy category, a few methods has been described about the quantification of rivastigmine in biological fluids which include the LC-MS, is an expensive instrumentation not available not available in conventional laboratory. Thus, it was decided to develop a precise, rapid, and accurate method which was based on liquid-liquid extraction for sample preparation UV detection for quantification of Rivastigmine from spiked human plasma.

Corresponding Author:- K. Bhavyasri.

Address:- Department of Pharmaceutical Analysis, RBVRR Women's College of Pharmacy, Barkatpura, Hyderabad, India. 
STRUCTURE: fig1: RIVASTIGMINE

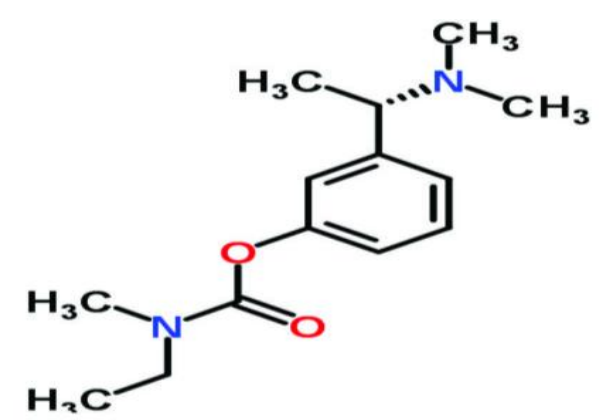

3.Introduction to UV Visible Spectrophotometer: UV spectroscopy is type of absorption spectroscopy in which light of ultra-violet region (200-400 nm.) is absorbed by the molecule. Absorption of the ultra-violet radiations results in the excitation of the electrons from the ground state to higher energy state. The energy of the ultra-violet radiation that are absorbed is equal to the energy difference between the ground state and higher energy states (delta $\mathrm{E}=\mathrm{hf}$ ). Generally, the most favored transition is from the highest occupied molecular orbital (HOMO) to lowest unoccupied molecular orbital (LUMO). For most of the molecules, the lowest energy occupied molecular orbitals are $\mathrm{s}$ orbital, which correspond to sigma bonds. The $\mathrm{p}$ orbitals are at somewhat higher energy levels, the orbitals (nonbonding orbitals) with unshared paired of electrons lie at higher energy levels. The unoccupied or antibonding orbitals (pie* and sigma*) are the highest energy occupied orbitals. In all the compounds (other than alkanes), the electrons undergo various transitions. Some of the important transitions with increasing energies are: nonbonding to pie $^{*}$, nonbonding to sigma ${ }^{*}$, pie to pie ${ }^{*}$, sigma to pie ${ }^{*}$ and sigma to sigma ${ }^{*}$.

UV spectroscopy obeys the Beer-Lambert law, which states that: when a beam of monochromatic light is passed through a solution of an absorbing substance, the rate of decrease of intensity of radiation with thickness of the absorbing solution is proportional to the incident radiation as well as the concentration of the solution.

The expression of Beer-Lambert law is-

$\mathrm{A}=\log \left(\mathrm{I}_{0} / \mathrm{I}\right)=\mathrm{Ecl}$

Where, $\mathrm{A}=$ absorbance

$\mathrm{I}_{0}=$ intensity of light incident upon sample cell

$\mathrm{I}=$ intensity of light leaving sample cell

$\mathrm{C}=$ molar concentration of solute

$\mathrm{L}=$ length of sample cell $(\mathrm{cm}$.)

$\mathrm{E}=$ molar absorptivity

From the Beer-Lambert law it is clear that greater the number of molecules capable of absorbing light of a given wavelength, the greater the extent of light absorption. This is the basic principle of UV spectroscopy.

\section{Bioanalytical method:}

Bioanalytical method development is the process of making a procedure to unknown compound or novel compound be identified and measured in a matrix. A compound can often be measured by several methods and the choice of analytical method involves, that is, chemical properties of the analyte, concentrations, sample matrix, cost of the analysis method and instruments, speed and time of the analysis, quantitative or qualitative measurement, precision and necessary equipment. Method development includes sample preparation sampling, separation, detection and evaluation of the results and conclusion.

The bioanalytical method involves the extraction process, which are as follows;

\subsection{Liquid-liquid extraction:}

It is based on the principles of difference solubility and partitioning equilibrium of analyte molecules between aqueous (the sample) and the organic phases.it generally involves the extraction of a substance from one liquid phase to additional liquid phase. 


\subsection{Solid phase extraction:}

SPE is choosy method for sample preparation where the analyte is bound onto a solid support, interferences are washed off and the analyte is selectively eluted. Solid phase includes four steps; conditioning, sample loading, washing and elution.

\subsection{Protein precipitation:}

Protein precipitation is widely used in routinely analysis to remove proteins. Precipitation can be induced by the addition of an organic modernizer, a salt or by changing the $\mathrm{pH}$. which influences the solubility of the proteins and the samples are centrifuged, supernatant can be used.

\section{Experimental:}

5.1 Equipment and materials: The analysis was performed using the uv sl120, pharmaceutical grade rivastigmine were kindly supplied as a gift sample from the pharma company, Hyderabad, Telangana, India. Human plasma was procured from the healthy human voluntaries. The chemicals such as n-butanol, methanol and Acetonitrile used in analysis were of hplc grade procured from Rankem Company.

\section{Procedure}

\section{Selection of wavelength}

$10 \mathrm{mg}$ of rivastigmine drug was accurately weighed and transferred into $10 \mathrm{ml}$ of volumetric flask and the volume was made up to the mark with methanol as diluent .Then from this $0.1 \mathrm{ml}$ was pipetted out and transferred into another $10 \mathrm{ml}$ volumetric flask and the volume was made up to the mark with methanol to give $10 \mathrm{ppm}$ solution and this was scanned between 200 to $400 \mathrm{~nm}$ and its absorbance was measured at 270nm.(Figure-1).

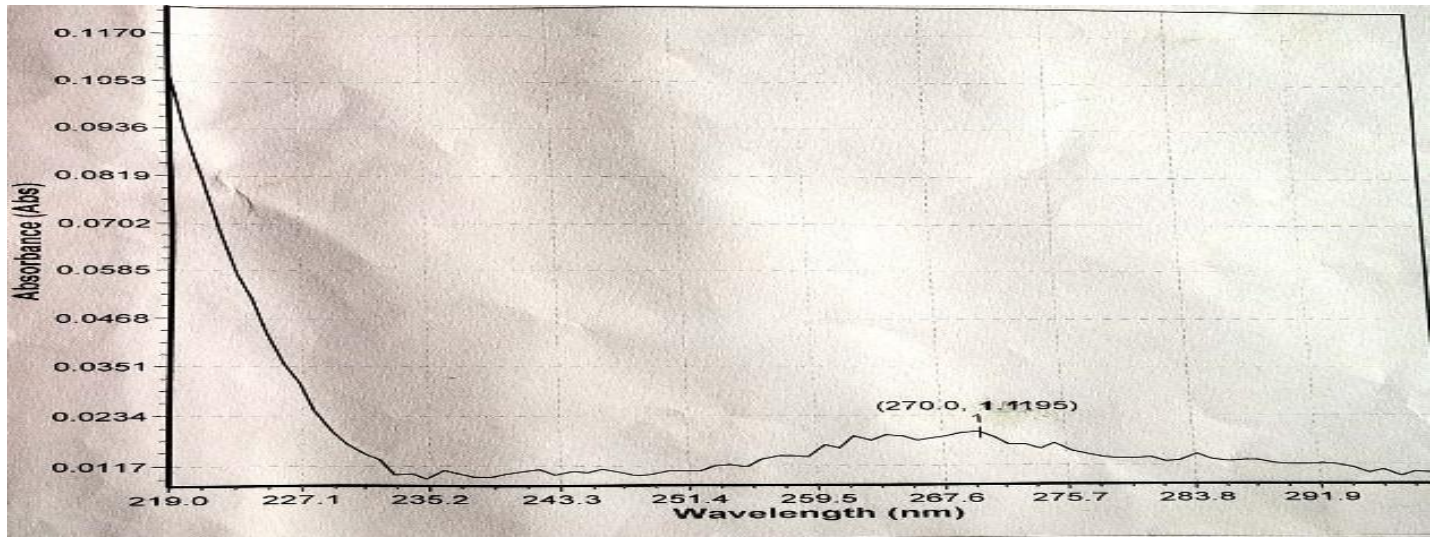

Figure-1: UV spectrum of rivastigmine

\section{Assay}

\section{Standard preparation}

$10 \mathrm{mg}$ of rivastigmine drug was accurately weighed and transferred into $10 \mathrm{ml}$ of volumetric flask and the volume was made up to the mark with methanol to get concentration of $1000 \mathrm{ppm}$.From this $0.1 \mathrm{ml}$ was pipetted out and transferred into $10 \mathrm{ml}$ of volumetric flask and the volume was made up to the mark to get $10 \mathrm{ppm}$ solution and its absorbance was measured at $270 \mathrm{~nm}$.

\section{Test preparation}

20 tablets were weighed and powdered. Powdered tablet equivalent to $10 \mathrm{mg}$ of rivastigmine was weighed accurately and it was taken into $10 \mathrm{ml}$ volumetric flask then volume was made up to the mark with methanol. From the above solution $0.1 \mathrm{ml}$ of solution was pipetted out and taken in $10 \mathrm{ml}$ volumetric flask. The volume was made up to $10 \mathrm{ml}$ to get $10 \mathrm{ppm}$ solution and its absorbance was measured at $270 \mathrm{~nm}$.

The $\%$ Assay is calculated by using the following formula

$\%$ Assay $=(($ absorbance of the sample/absorbance of the standard $) *($ concentration of the standard/concentration of the sample) $) * 100$ 
Methods: preparation of standard solutions:

Preparation of stock solution:10mg of pure Rivastigmine was accurately weighed and transferred into $10 \mathrm{ml}$ volumetric flask and volume was made up to the mark by using the methanol as diluent to give 1000ppm concentration.

Preparation of standard: From the stock $0.1 \mathrm{ml}$ was pipetted out and transferred in to $10 \mathrm{ml}$ volumetric flask and the volume was made up to the mark by using the methanol as a diluent to give $10_{\mathrm{ppm}}$ concentration and its absorbance is noted by measuring at $270 \mathrm{~nm}$.

Extraction procedure: Extraction was performed by taking $20 \mathrm{ul}$ of $1 \mathrm{M} \mathrm{NaoH}$ and $3 \mathrm{ml}$ of 1-butanol/n-hexane $(2: 98 \mathrm{v} / \mathrm{v})$ to $1 \mathrm{ml}$ of plasma in $4.5 \mathrm{ml}$ polypropylene tube and shaken for 2 minutes. After centrifugation at $6000 \mathrm{~g}$ for $2 \mathrm{~min}$, the whole organic layer was separated and transferred in to $4.5 \mathrm{ml}$ tube. Then, $100 \mathrm{ul}$ of $0,1 \%$ acetic acid was added. the mixture was vortex -mixed for 2 min, the upper organic phase was discarded completely and aqueous phase was taken and its absorbance is measured at $270 \mathrm{~nm}$.

\section{Method validation parameters:}

Linearity: calibration standard solutions were prepared in plasma from the working solutions. Five calibration curves ranging from the $6,9,12,15$ and $18 \mathrm{ppm}$ were run to establish the linearity by using linear regression analysis. $0.6 \mathrm{ml}$ of standard solution was pipetted in $10 \mathrm{ml}$ volumetric flask and Volume was made up to the mark to give 6ppm concentration. Similarly, concentrations of $9 \mathrm{ppm}, 12 \mathrm{ppm}, 15 \mathrm{ppm}$ and $18 \mathrm{ppm}$ was prepared. And absorbance was measured at $270 \mathrm{~nm}$.

Accuracy: quality control of samples was prepared at four different levels. The concentration of rivastigmine was calculated from a standard calibration curve that was concurrently obtained. Accuracy was analyzed at each level by comparing the observed concentration as a mean relative percentage recovery. $2 \mathrm{ml}$ of standard solution was spiked with $4 \mathrm{ml}$ of sample solution, $2 \mathrm{ml}$ of standard solution was spiked with $6 \mathrm{ml}$ of sample solution, $2 \mathrm{ml}$ of standard solution was spiked with $8 \mathrm{ml}$ of sample solution. Absorbance was measured for three times at $270 \mathrm{~nm}$.

Robustness: Robustness: 6 aliquots of $6 \mathrm{ppm}$ of standard solution was prepared and it was scanned at wavelength at $( \pm) 1 \mathrm{~nm}$ of $\lambda \max$. The absorbance was noted down.

\section{Results and Discussion:-}

\section{Linearity study of Rivastigmine}

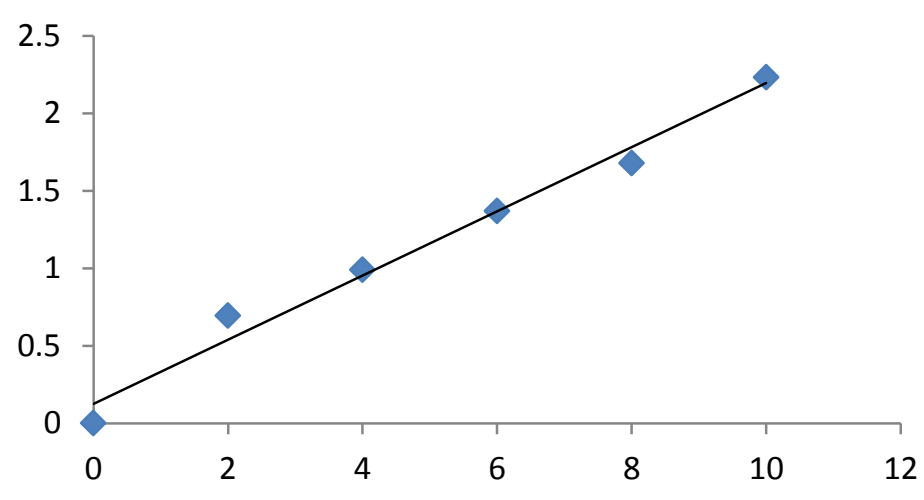

$\mathrm{y}=0.2071 \mathrm{x}+0.1249$ $\mathrm{R}^{2}=0.9828$

Figure 2 : Linearity curve of rivastigmine 
Table-1: Conc. Vs Abs. table for Linearity Study

\begin{tabular}{|l|l|}
\hline Concentration(ppm) & Absorbance(nm) \\
\hline 0 & 0 \\
\hline 6 & 0.6933 \\
\hline 9 & 0.9895 \\
\hline 12 & 1.3691 \\
\hline 15 & 1.6791 \\
\hline 18 & 2.2325 \\
\hline
\end{tabular}

\begin{tabular}{|l|l|}
\hline Sample no. & \% RSD \\
\hline 1 & 0.9896 \\
\hline 2 & 0.9894 \\
\hline 3 & 0.9885 \\
\hline 4 & 0.9879 \\
\hline 5 & 0.9872 \\
\hline 6 & 0.9869 \\
\hline Mean & 0.9883 \\
\hline SD & 0.001118 \\
\hline$\%$ RSD & 0.001131 \\
\hline
\end{tabular}

Table-2: Evaluation data of precision study.

\begin{tabular}{|c|c|c|}
\hline \% Recovery level & \%Recovery & Mean \% recovery \\
\hline \multirow[t]{3}{*}{$50 \%$} & 99.52 & \multirow[t]{3}{*}{99.53} \\
\hline & 99.62 & \\
\hline & 99.50 & \\
\hline \multirow[t]{3}{*}{$100 \%$} & 99.58 & \multirow[t]{3}{*}{99.61} \\
\hline & 99.69 & \\
\hline & 99.58 & \\
\hline \multirow[t]{3}{*}{$150 \%$} & 99.76 & \multirow[t]{3}{*}{99.76} \\
\hline & 99.65 & \\
\hline & 99.80 & \\
\hline
\end{tabular}

Table-3: Evaluation data of accuracy study.

The limit of detection was found to be $0.51 \mathrm{ppm}$ and limit of quantification found to be $1.57 \mathrm{ppm}$.

\begin{tabular}{|l|l|l|l|}
\hline Sample no. & $\mathbf{2 6 9 n m}$ & $\mathbf{2 7 0 n m}$ & $\mathbf{2 7 1 n m}$ \\
\hline 1 & 1.0188 & 1.1190 & 1.2194 \\
\hline 2 & 1.0185 & 1.1187 & 1.2186 \\
\hline 3 & 1.0178 & 1.1181 & 1.2180 \\
\hline 4 & 1.0182 & 1.1179 & 1.2175 \\
\hline 5 & 1.0174 & 1.1171 & 1.2170 \\
\hline 6 & 1.0167 & 1.1163 & 1.2160 \\
\hline Mean & 1.018 & 1.118 & 1.218 \\
\hline SD & 0.0007694 & 0.001007 & 0.001200 \\
\hline \%RSD & 0.07558 & 0.09007 & 0.09852 \\
\hline
\end{tabular}

Table-4: Evaluation data of robustness study.

\section{Acknowledgement:-}

The author would like to express her gratitude to Dr.K.Bhavyasri for her guidance and reviews, grateful to RBVRR Women's College of pharmacy for help and support. 


\section{References:-}

1. Winblad, B.; Grossberg, G.; Frölich, L.; Farlow, M.; Zechner, S.; Nagel, J.; Lane, R. (2007). "IDEAL: A 6month, double-blind, placebo-controlled study of the first skin patch for Alzheimer disease". Neurology.

2. Camps P, Munoz-Torrero D: Cholinergic drugs in pharmacotherapy of Alzheimer's disease. Mini Rev Med Chem. 2002;2(1):11-25.

3. Rosler M, Anand R, Cicin-Sain A, Gauthier S, Agid Y, Dal-Bianco P, Stahelin HB, Hartman R, Gharabawi M: Efficacy and safety of rivastigmine in patients with Alzheimer's disease: international randomized controlled trial. BMJ. 1999 6;318(7184):633-8.

4. Finkel SI: Effects of rivastigmine on behavioral and psychological symptoms of dementia in Alzheimer's disease. Clin Ther. 2004;26(7):980-90.

5. Rosler M, Retz W, Retz-Junginger P, Dennler HJ: Effects of two-year treatment with the cholinesterase inhibitor rivastigmine on behavioural symptoms in Alzheimer's disease. Behav Neurol. 1998;11(4):211-216.

6. Emre M, Aarsland D, Albanese A, Byrne EJ, Deuschl G, De Deyn PP, Durif F,Kulisevsky J, van Laar T, Lees A, Poewe W, Robillard A, Rosa MM, Wolters E, Quarg P, Tekin S, Lane R: Rivastigmine for dementia associated with Parkinson's disease. N Engl J Med. 2004 Dec 9;351(24):2509-18.

7. Birks J, Grimley Evans J, Iakovidou V, Tsolaki M, Holt FE: Rivastigmine for Alzheimer's disease. Cochrane Database Syst Rev. 2009

8. Naik RS, Hartmann J, Kiewert C, Duysen EG, Lockridge O, Klein J: Effects of rivastigmine and donepezil on brain acetylcholine levels in acetylcholinesterase-deficient mice. J Pharm Pharm Sci. 2009;12(1):79-85.

9. Farlow MR: Update on rivastigmine. Neurologist. 2003 Sep;9(5):230-4.

10. Skoog, Douglas A.; Holler, F. James; Crouch, Stanley R. (2007). Principles of Instrumental Analysis (6th ed.). Belmont, CA: Thomson Brooks/Cole. pp. 169-173.

11. Misra, Prabhakar; Dubinskii, Mark, eds. (2002). Ultraviolet Spectroscopy and UV Lasers. New York: Marcel Dekker. ISBN 978-0-8247-0668-5.

12. Metha, Akul (14 May 2012). "Limitations and Deviations of Beer-Lambert Law". PharmaXChange.info.

13. Puluido A, Ruusanches I, Boque R, Rius FX. Uncertainty of results in routine qualitative analysis in analytical chemistry. J Pharm Biomed Anal 2005; 22:647-54

14. Lang JR, Bolton S. A comprehensive method validation strategy for bioanalytical applications in the pharmaceutical industry--1. Experimental considerations. J Pharm Biomed Anal 1991;9(5):357-61

15. Shah VP. The history of bioanalytical method validation and regulation: Evolution of a guidance document on bioanalytical method validation. AAPS J 2007;9(1):43-7

16. Buick AR, Doig MV, Jeal SC, Land GS, McDowall RD. Method validation in the bioanalytical laboratory. J Pharm Biomed Anal 1990;8(8-12):629-37

17. Tiwari G, Tiwari R. Bioanalytical method validation: An updated review. Pharm Methods 2010;1(1):25-38 